\title{
Overweight - obesity is associated with decreased vitamin K2 levels in hemodialysis patients
}

\author{
Maura Ravera, Thomas Nickolas, Mario Plebani, Giorgio lervasi, Andrea Aghi, \\ Pascale Khairallah, Maurizio Gallieni, Maria Cristina Mereu, Sandro Giannini, \\ Stefania Sella, Martina Zaninotto, Ernesto Paoletti, Elisabetta Bussalino, Luca Di Lullo, \\ Antonio Bellasi, Laura Cosmai, Marina Foramitti, Fabio Malberti, Maria Luisa Brandi, \\ Serge Ferrari, Giovanni Tripepi and Maria Fusaro*
}

Maura Ravera, Ernesto Paoletti and Elisabetta Bussalino: Policlinico San Martino, Genoa, Italy. Thomas Nickolas and Pascale Khairallah: Department of Medicine, Division of Nephrology, Columbia University Medical Center, New York, NY, USA. Mario Plebani and Martina Zaninotto: Laboratory Medicine Unit, Department of Medicine, University of Padua, Padua, Italy. Giorgio Iervasi: National Research Council (CNR), Institute of Clinical Physiology (IFC), Pisa, Italy. Andrea Aghi, Sandro Giannini and Stefania Sella: Department of Medicine, Clinica Medica 1, University of Padua, Padua, Italy. Maurizio Gallieni: Nephrology and Dialysis Unit, ASST Fatebenefratelli Sacco, Department of Clinical and Biomedical Sciences 'Luigi Sacco', University of Milan, Milan, Italy. Maria Cristina Mereu: Nephrologist Independent Researcher, Cagliari, Italy. Luca Di Lullo: Department of Nephrology and Dialysis, Parodi-Delfino Hospital, Colleferro, Rome, Italy. Antonio Bellasi:

Department of Research, Innovation, Brand Reputation, Bergamo Hospital, ASST Papa Giovanni XXIII, Bergamo, Italy. Laura Cosmai: Nephrology and Dialysis Unit, San Carlo Borromeo Hospital, ASST Santi Paolo e Carlo, Milan, Italy. Marina Foramitti and Fabio Malberti: Nephrology and Dialysis Unit, ASST Cremona, Cremona, Italy. Maria Luisa Brandi: Department of Biomedical Experimental and Clinical Sciences, University of Florence, Florence, Italy. Serge Ferrari: Department of Medicine, Service of Bone Diseases, Geneva University Hospital and Faculty of Medicine, Geneva, Switzerland. Giovanni Tripepi: CNR-IFC, Clinical Epidemiology of Renal Diseases and Hypertension, Ospedali Riuniti, Reggio Calabria, Italy

\footnotetext{
*Corresponding author: Maria Fusaro, MD, PhD, National Research

Council (CNR), Institute of Clinical Physiology (IFC), Pisa Via G.

Moruzzi 1, 56124, Pisa, PI, Italy; and Department of Medicine,

University of Padua, Via Giustiniani 2, 35128 Padova, PD, Italy,

E-mail: dante.lucia11@gmail.com
} 
Introduction

Obesity is a global epidemic, and its prevalence has nearly tripled between 1975 and 2016. Obesity is also associated with higher risk of type 2 diabetes mellitus, dyslipidemia, arterial hypertension and CKD [1-3]. In end-stage renal disease (ESRD), large epidemiologic studies reported a U-shaped association between body mass index (BMI) and death [4, 5]. Although proposed mechanisms for this "obesity paradox" [5] in hemodialysis patients include comorbidities and malnutrition, identification of biochemical mediators, possibly associated with adverse outcomes, is needed in dialysis patients.

Vitamin $\mathrm{K}$ is a fat-soluble vitamin existing in two biologically active forms: vitamin $\mathrm{K} 1$ or phylloquinone and vitamin K2 or menaquinone, which includes 12 different menaquinones (from MK2 to MK11) [6], the most studied of which are MK4 and menaquinone-7 (MK7) $[7,8]$. Vitamin K acts as the coenzyme of a carboxylase that determines carboxylation of glutamic acid residues, resulting in the formation of the amino acid g-carboxy-glutamic acid (Gla). In the liver, this reaction controls the production of vitamin K-dependent proteins (VKDPs), such as coagulation factors, and in extrahepatic tissues the VKDPs, bone and matrix Gla proteins (BGP and MGP, respectively) $[7,8]$. BGP is a small protein produced by osteoblasts under the control of vitamin D. It contains three GLA residues that enable its binding to hydroxyapatite in bone [9].

BGP knockout mice develop hyperostosis, showing that it has a role in promoting normal bone mineralization [10].Vitamin $\mathrm{K}$ deficiency in bone can be measured indirectly by measuring undercarboxylated BGP (UCBGP). MGP is a potent inhibitor of vascular calcification (VC), and it is produced by osteoclasts, chondrocytes and vascular smooth muscle cells (VSMCs) [11]. MGP knockout mice experience pathological fractures due to severe osteoporosis and widespread VC [12].

In a secondary analysis of the VIKI study, we evaluated the relationship between vitamin $\mathrm{K}$ levels and $\mathrm{BMI}$ value in hemodialysis patients according to the hypothesis that the impact of BMI on mortality is in part driven by low vitamin $\mathrm{K}$ levels (Figure 1).

\section{Materials and methods}

This study is a secondary analysis of the VIKI study, involving 18 dialysis centers in Italy [13]. Ethics committees were approved for the study (approval dates ranged from July 14, 2008 to October 26, 2009), in accordance with the regulations in place related to observational studies. Patient enrollment took place between November 2008 and November 2009, and follow-up to assess vital status was performed in December 2011. We included adult patients of both genders who had been on hemodialysis for $>1$ year, provided that they gave their informed consent, in writing, for the use of their medical records for the study. We excluded patients who had a life expectancy $<6$ months, cancer (with the exception of basal cell carcinoma), coagulation disorders or conditions that, according to the investigator, could interfere with the study outcome. We collected the following information: demographic data (initials or ID number, gender, age); renal failure history (cause, type of hemodialysis, duration of hemodialysis in months, transplantation history); lifestyle (smoking status, alcohol consumption) and medical history. BMI was classified into the following categories: underweight (BMI $<18.5 \mathrm{~kg} / \mathrm{m} 2)$, normal weight $(18.5 \leq \mathrm{BMI}<25 \mathrm{~kg} / \mathrm{m} 2)$, overweight $(25 \leq \mathrm{BMI}<30$ $\mathrm{kg} / \mathrm{m} 2$ ) and obese (BMI $\geq 30 \mathrm{~kg} / \mathrm{m} 2)$. 
Laboratory determination

Parathyroid hormone (PTH)

The method for quantitative determination of PTH in serum was the automated LIAISON ${ }^{\circledR} \mathrm{N}$-Tact ${ }^{\circledR}$ PTH Assay 310910 (DiaSorin Inc., Stillwater, MN, USA), a direct, two-site, sandwich-type chemiluminescence immunoassay (CLIA) carried out on the LIAISON ${ }^{\circledR}$ (DiaSorin Inc., Stillwater, MN, USA) instrument. The analytical sensitivity was $1 \mathrm{pg} / \mathrm{mL}$ and the intra-assay and inter-assay coefficients of variation (CVs) were $3.7-6.3$ and $3.5 \%-5.3 \%$, respectively.

\section{$25-\mathrm{OH}$ vitamin D}

For quantitative determination of total $25-\mathrm{OH}$ vitamin D (both D2 and D3 form) in serum, we used the automated LIAISON ${ }^{\circledR} 25 \mathrm{OH}$ Vitamin D TOTAL Assay 310600, a direct competitive CLIA executed on the LIAISON (DiaSorin Inc., Stillwater, MN, USA) instrument. The analytical sensitivity was $<10$ $\mathrm{nmol} / \mathrm{L}$, and the intra-assay CV was between $2.9 \%$ and $5.5 \%$, while the inter-assay CV was $6.3 \%$ $12.9 \%$.

Total BGP

The method for the quantitative determination of total BGP in serum was the automated LIAISON ${ }^{\circledR}$ Osteocalcin Assay 310950 (DiaSorin Inc., Stillwater, MN, USA), a direct, two-site, sandwich-type CLIA executed on the LIAISON ${ }^{\circledR}$ (DiaSorin Inc., Stillwater, MN, USA) instrument. The analytical sensitivity was $<0.3 \mathrm{ng} / \mathrm{mL}$ and the intra-assay CV was $3 \%-8 \%$, while the inter-assay CV was $4 \%-9 \%$.

Undercarboxylated BGP (ucBGP)

For quantitative determination of the ucBGP, we used the Glu-osteocalcin Enzyme Immuno Assay (EIA) Kit MK118 (Takara Bio Inc., Otsu, Shiga, Japan), a manual solidphase EIA based on a sandwich method that utilizes two mouse monoclonal anti-UcBGP antibodies to detect ucBGP by a two-step procedure. One of the mouse monoclonal anti-ucBGPs is immobilized onto the micro-titer plate and blocked against non-specific binding. Samples are added to each well and incubated. The second step is to wash the plate and to add the second anti-BGP labeled with per-oxidase (POD). The reaction between $\mathrm{POD}$ and substrate ( $\mathrm{H} 2 \mathrm{O} 2$ and $3,3^{\prime}, 5,5^{\prime}$ tetramethyl-benzidine) results in color development with intensities proportional to the amount of ucBGP present. The analytical sensitivity was $0.25 \mathrm{ng} / \mathrm{mL}$ and the intra-assay and inter-assay CVs were $4.4-6.7$ and $5.7 \%-9.9 \%$, respectively.

Total matrix GLA protein (MGP)

The quantitative determination of MGP was performed using the Human MGP-Matrix Gla Protein Kit (Biomedica Medizinprodukte GmbH \& Co KG, Wien, Austria). It is a manual competitive ELISA method designed to detectMGP in serum. The analytical sensitivity was $0.3 \mathrm{nmol} / \mathrm{L}$, and the intraassay and inter-assay CVs were $5 \%-6 \%$ and $7 \%-9 \%$, respectively.

Undercarboxylated MGP (ucMGP)

The measurement of the total uCMGP was performed by VitaK using a competitive ELISA, as described previously [14]. The analytical sensitivity was $21 \mathrm{nmol} / \mathrm{L}$, and the intra-assay and interassay CVs have been found to be $8.9 \%$ and $11.4 \%$, respectively.

We also measured vitamin $\mathrm{K}$ components (see Appendix).

Statistics 
Data are summarized as mean \pm standard deviation (SD) for normally distributed variables or as median and interquartile range (IQ) for non-normally distributed variables, and percentages for all categorical variables. The normal distribution of continuous variables was tested by the Shapiro-Wilk test. Categorical variables across BMI groups were analyzed by the chi-squared $(\chi 2)$ test or Fisher's exact method. Continuous variables among more than two groups were compared by the one-way ANOVA or the Kruskall-Wallis tests, as appropriate. To assess the independent correlates of BGP and MK7/triglycerides (dependent variables), multiple linear regression models were built up by including all variables which resulted to be associated with the outcome variables with a $p<0.10$ at univariate analysis. All statistical analyses were performed using statistical SPSS 15.0 package. A value of $p<0.05$ was considered statistically significant.

Results

Baseline characteristics of patients classified on the basis of BMI categories are presented in Table 1. $45.72 \%$ were overweight or obese, $4.39 \%$ were underweight and $50.39 \%$ had normal weight. A high prevalence of underweight women ( $82 \%$ in the group with BMI less than $18.5 \mathrm{~kg} / \mathrm{m} 2$ ) was observed. Obese and overweight patients had higher prevalence of diabetes and shorter dialysis vintage than patients who were underweight or with normal weight.

Higher triglycerides and lower HDL levels were observed in obese and overweight patients; these patients received statins (41.7\%), oral antidiabetic drugs (4\%) and insulin (21.7\%). There were no between-group differences in medications aimed at correcting MBD-CKD, namely calcium carbonate, sevelamer, lanthanum, calcitriol, vitamin D analogs and calciomimetics (Table 2).

On univariate analyses, total and ucBGP levels were inversely related to BMI (Figure 2). By contrast, no association was found between this metric and total MGP and ucMGP (Table 1). Obese patients had higher $\mathrm{K} 1$ and $\mathrm{K} 1 /$ triglycerides levels as compared to underweight patients. Furthermore, obese patients had lower MK7/triglycerides levels than normal weight patients (Figure 3 and Table 3). Multiple regression analysis adjusted for a series of potential confounders showed that BMI was independently related to MK7/triglycerides levels $(\beta=-0.159 ; p=0.003$ ) (Table 4 ) and this was also when the same analysis was carried out according to BGP $(\beta=-0.119 ; p=0.012)$ (Table 5).

\section{Discussion}

We found that obese hemodialysis patients had lower MK7 levels as compared to non-obese patients. These are the first data to demonstrate an inverse relationship between MK7 (Vitamin K2) and $\mathrm{BMI}$ in hemodialysis patients. Furthermore, in our study, total BGP concentrations have been shown to be reduced in patients with greater BMI. Vitamin K deficiency and obesity are both risk factors for cardiovascular diseases in CKD patients. MK7 is the most widely known menaquinone. It is present in fermented and some animal-derived foods, and it has greater bioavailability than other forms of vitamin K. MK7 is used as a dietary supplement secondary to its beneficial role in human health [15]. A prospective population-based study of 4807 subjects without clinical history of myocardial infarction, followed for 7 years, showed indeed that intake of menaquinone resulted in a significant risk reduction in coronary heart disease, all-cause mortality and severe aortic calcification [16].

Obesity prevalence has been reported in $30 \%$ of the US dialysis population, and it was found associated with increased risk for adverse outcomes, death and worsening of CKD [3, 14, 17-19]; it is also associated with earlier and progressive bone disorders, such as osteoporosis and fractures [19]. 
In hemodialysis patients, we previously reported higher prevalence of vitamin $\mathrm{K}$ deficiency (up to $35 \%$ ) as compared to the general population [20-22]. In particular, lower MK7 levels was an independent predictor of iliac artery calcifications (OR 1.64), whereas MK4 deficiency was associated as predictors for aortic calcification. These findings support the role of vitamin $\mathrm{K}$ as an inhibitor of $\mathrm{VC}$ in the vessel wall $[13,23]$. Indeed, the active MGP form (phosphorylated carboxylated: $p$-cMGP) proved to be effective in solubilizing circulating calcium crystals binding to a circulating fetuin- $A$ complex. Moreover, p-cMGP has been demonstrated to inhibit the pro-osteoblastic transcription factor BMP-2 able to induce apoptosis and trans-differentiation of VSMCs into osteoblast-like cells [24]. BGP can exert a protective role on VCs through intriguing mechanism where BGP increases adiponectin secretion. The latter is an anti-inflammatory protein secreted by adipocytes and in the arterial wall, prevents the transdifferentiation of VSMCs into osteoblast-like cells in arterial media [25-27], thus protecting from VC development.

In the MINOS study (774 men in osteoporosis), low total BGP levels have been shown to be a predictor of cardiovascular mortality, whereas higher total BGP concentrations are associated with lower abdominal aortic calcification progression rate and lower 10-year all-cause mortality (MINOS) [27].

In conclusion, we found an association between decreased vitamin K2 and obesity. Interventional studies with vitamin $\mathrm{K}$ supplementation in obese CKD subjects are warranted to confirm the potential role of low levels of vitamin $\mathrm{K}$ as a modifiable risk factor for the high morbidity and mortality in obese CKD patients.

\section{Appendix}

\section{Laboratory determination}

The Laboratory in Perugia determined vitamin K components by a simple, sensitive and selective reversed-phase high-performance liquid chromatography (HPLC) method, developed for the simultaneous determination of vitamin $\mathrm{K}$ in human plasma. Clear and well-separated chromatographic PK and MK profiles were obtained in healthy human and uremic plasma [13].

The adjustment for triglycerides concentration is particularly relevant for the assessment of vitamin $\mathrm{K}$ status. Vitamin $\mathrm{K}$ components are all liposoluble compounds that become part of chylomicrons after absorption from the gut and as such are transported to the liver. Vitamin K1 remains partly in the liver, whereas vitamin $\mathrm{K} 2$ is transferred to VLDL and LDL for transport and there is a close correlation ( $r=0.99$ ) between triglycerides concentrations and vitamin K1 [13]. Uremic plasma is characterized by an increased level of plasma lipids and lipoproteins, which are interfering factors to chromatography. Thus, we adopted a liquid-liquid extraction and then a solid-phase extraction of human plasma using polymeric reversed-phase cartridges, achieving good reproducibility. The vitamers were measured by an electrochemical detector after postcolumn reduction with platinum on alumina powder and using the MK8 form as the internal standard. Quantitative recovery was obtained in the range of $80 \%-96 \%$ for PK and MK vitamers. Vitamin $\mathrm{K}$ values were corrected according to triglycerides levels [13].

Author contributions: All authors contributed to the study conception and design. Material preparation, data collection and analysis were performed by Maria Fusaro, Andrea Aghi and Giovanni Tripepi. The first draft of the manuscript was written by Maura Ravera and Maria Fusaro, 
and all authors commented on previous versions of the manuscript. All authors read and approved the final manuscript. Research funding: None declared.

Employment or leadership: None declared.

Honorarium: None declared.

Competing interests: Authors state no conflict of interest. Informed consent: Informed consent was obtained from all individuals included in this study.

Ethical approval: All procedures performed in studies involving human participants were in accordance with the ethical standards of the Institutional Research Committee and with the 1964 Helsinki Declaration and its later amendments or comparable ethical standards.

\section{References}

1. World Health Organization. https://www.who.int/news-room/ fact-sheets/detail/obesity-andoverweight. Accessed 07 May 2019.

2. NCD Risk Factor Collaboration (NCD-RisC). Worldwide trends in body-mass index, underweight, overweight, and obesity from 1975 to 2016: a pooled analysis of 2416 population-based measurement studies in 128 - 9 million children, adolescents, and adults. Lancet 2017;390:2627-42.

3. Kovesdy CP, Furth SL, Zoccali C, World Kidney Day Steering Committee. Obesity and kidney disease: hidden consequences of the epidemic. Can J Kidney Health Dis 2017;4:2054358117698669.

4. Beddhu S, Pappas LM, Ramkumar N, Samore M. Effects of body size and body composition on survival in hemodialysis patients. J Am Soc Nephrol 2003;14:2366-72.

5. Kalantar-Zadeh K, Rhee CM, Chou J, Ahmadi SF, Park J, Chen JL, et al. The obesity paradox in kidney disease: how to reconcile it with obesity management. Kidney Int Rep 2017;2:271-81.

6. Shearer MJ, Newman P. Recent trends in the metabolism and cell biology of vitamin $\mathrm{K}$ with special reference to vitamin K cycling and MK-4 biosynthesis. J Lipid Res 2014;55:345-62.

7. Shearer MJ, Newman P. Metabolism and cell biology of vitamin K. Thromb Haemost 2008;100:530-47.

8. Fusaro M, Mereu MC, Aghi A, lervasi G, Gallieni M. Vitamin K and bone. Clin Cases Miner Bone Metab 2017;14:200-6.

9. Fusaro M, Crepaldi G, Maggi S, Galli F, D’Angelo A, Calò L, et al. Vitamin K, bone fractures, and vascular calcifications in chronic kidney disease: an important but poorly studied relationship. J Endocrinol Invest 2011;34:317-23.

10. Ducy P, Desbois C, Boyce B, Pinero G, Story B, Dunstan C, et al. Increased bone formation in osteocalcin-deficient mice. Nature 1996;382:448-52.

11. Schurgers LJ, Cranenburg EC, Vermeer C. Matrix Gla-protein: the calcification inhibitor in need of vitamin K. Thromb Haemost 2008;100:593-603.

12. Luo G, Ducy P, McKee MD, Pinero GJ, Loyer E, Behringer RR, et al. Spontaneous calcification of arteries and cartilage in mice lacking matrix GLA protein. Nature 1997;386:78-81. 
13. Fusaro M, Noale M, Viola V, Galli F, Tripepi G, Vajente N, et al. Vitamin K, vertebral fractures, vascular calcifications, and mortality: vltamin K Italian (VIKI) dialysis study. J Bone Miner Res 2012;27:2271-8.

14. Hoogeveen EK, Halbesma N, Rothman KJ, Stijnen T, van Dijk S, Dekker FW, et al. Obesity and mortality risk among younger dialysis patients. Clin J Am Soc Nephrol 2012;7:280-8.

15. Marles RJ, Roe AL, Oketch-Rabah HA. US Pharmacopeial convention safety evaluation of menaquinone-7, a form of vitamin K. Nutr Rev 2017;75:553-78.

16. Geleijnse JM, Vermeer C, Grobbee DE, Schurgers LJ, Knapen MH, van der Meer IM, et al. Dietary intake of menaquinone is associated with a reduced risk of coronary heart disease: the Rotterdam Study. J Nut 2004;134:3100-5.

17. Schrauben SJ, Hsu JY, Wright Nunes J, Fischer MJ, Srivastava A, Chen J, et al. Health behaviors in younger and older adults with CKD: results from the CRIC study. Kidney Int Rep 2018;4:80-93.

18. Pommer W. Preventive nephrology: the role of obesity in different stages of chronic kidney disease. Kidney Dis (Basel) 2018;4:199-204.

19. Lespessailles E, Paccou J, Javier RM, Thomas T, Cortet B, GRIO Scientific Committee. Obesity, bariatric surgery and fractures. J Clin Endocrinol Metab 2019;104:4756-68.

20. Neogi T, Booth SL, Zhang YQ, Jacques PF, Terkeltaub R, Aliabadi $P$, et al. Low vitamin $\mathrm{K}$ status is associated with osteoarthritis in the hand and knee. Arthritis Rheum 2006;54:1255-61.

21. Neogi T, Felson DT, Sarno R, Booth SL. Vitamin K in hand osteoarthritis: results from a randomised clinical trial. Ann Rheum Dis 2008;67:1570-3.

22. Misra D, Booth SL, Tolstykh I, Felson DT, Nevitt MC, Lewis CE, et al. Vitamin K deficiency is associated with incident knee osteoarthritis. Am J Med 2013;126:243-8.

23. Wallin R, Schurgers L, Wajih N. Effects of the blood coagulation vitamin $\mathrm{K}$ as an inhibitor of arterial calcification. Thromb Res 2008;122:411-7.

24. Parker BD, Ix JH, Cranenburg EC, Vermeer C, Whooley MA, Schurgers LJ. Association of kidney function and uncarboxylated matrix Gla protein: data from the Heart and Soul Study. Nephrol Dial Transplant 2009;24:2095-101.

25. Luo XH, Zhao LL, Yuan LQ, Wang M, Xie H, Liao EY. Development of arterial calcification in adiponectin-deficient mice: adiponectin regulates arterial calcification. J Bone Miner Res 2009;24:1461-8.

26. Fusaro M, Gallieni M, Aghi A, Rizzo MA, lervasi G, Nickolas TL, et al. Osteocalcin (bone GLA protein) levels, vascular calcifications, vertebral fractures and mortality in hemodialysis patients with diabetes mellitus. J Nephrol 2019;32:635-43.

27. Confavreux CB, Szulc P, Casey R, Boutroy S, Varennes A, Vilayphiou N, et al. Higher serum osteocalcin is associated with lower abdominal aortic calcification progression and longer 10-year survival in elderly men of the MINOS cohort. J Clin Endocrinol Metab 2013;98:1084-92. 


\section{Figure Legend}

Figure 1: Interconnection between obesity and vitamin K levels (*Schurgers et al. [11]).

Figure 2: Total BGP levels by BMI.

Figure 3: MK7/triglycerides levels in obese and normal weight patients. 
Table 1. Main characteristics of the patients.

\begin{tabular}{|c|c|c|c|c|c|}
\hline Variable & $\begin{array}{r}\text { Patients underweight } \\
\text { BMI }<18.5 \\
(\mathrm{n}=17,4.39 \%) \\
\end{array}$ & $\begin{array}{r}\text { Patients normal } \\
\text { weight } 18.5 \leq \mathrm{BMI}<25 \\
(\mathrm{n}=195,50.39 \%)\end{array}$ & $\begin{array}{r}\text { Patients overweight } \\
25 \leq \mathrm{BMI}<30 \\
(\mathrm{n}=118,30.49 \%) \\
\end{array}$ & $\begin{array}{r}\text { Patients obese } \\
\text { BMI } 230 \\
(\mathrm{n}=57,14.73 \%) \\
\end{array}$ & p-Value \\
\hline Gender, female, $\mathbf{n}(\%)$ & $14(82.35 \%)$ & $77(39.49 \%)$ & $36(30.51 \%)$ & $18(31.58 \%)$ & $<0.001$ \\
\hline Age, years (medlan) & $71(54,72)$ & $68(53,74)$ & $68(55,74)$ & $65(58,70)$ & 0.717 \\
\hline Welght, kg, mean \pm SD (not normal dlstributed by all group) & $48.59 \pm 6.46$ & $62.27 \pm 8.71$ & $76.13 \pm 9.09$ & $91.38 \pm 11.29$ & $<0.001$ \\
\hline Welght, kg (medlan) & $46.5(43.5,53)$ & $61.5(57,68)$ & $75(70.3,81)$ & $89.5(85,99)$ & $<0.001$ \\
\hline Helght, mean \pm SD & $1.67 \pm 0.10$ & $1.67 \pm 0.09$ & $1.67 \pm 0.09$ & $1.67 \pm 0.09$ & 0.987 \\
\hline $\mathrm{BMI}, \mathrm{kg} / \mathrm{cm}^{2}$ (medlan) & $17.3(16.99,17.67)$ & $22.4(20.96,23.83)$ & $27.02(25.67,28.39)$ & $31.87(31.22,33.75)$ & $<0.001$ \\
\hline Smoker, $n(\%)(n=370)$ & & & & & 0.298 \\
\hline Yes & $14(93.33 \%)$ & $116(62.37 \%)$ & $72(62.61 \%)$ & $32(59.26 \%)$ & \\
\hline No & $0(0 \%)$ & $42(22.58 \%)$ & $29(25.22 \%)$ & $14(25.93 \%)$ & \\
\hline Ex & $1(6.67 \%)$ & $28(15.05 \%)$ & $14(12.17 \%)$ & $8(14.81 \%)$ & \\
\hline Current or former alcohol drinker, $n(\%)(n=361)$ & $2(12.50 \%)$ & $38(21.11 \%)$ & $30(26.32 \%)$ & $12(23.53 \%)$ & 0.557 \\
\hline \multicolumn{6}{|l|}{ Medical history } \\
\hline Dialysis vintage, months (median) & $93(54,126)$ & $55(29,102)$ & $45(26,88)$ & $39(26,60)$ & $<0.004$ \\
\hline Type of dlalysis, n (\%) & & & & & 0.613 \\
\hline BIcarbonate dialysls & $12(70.59 \%)$ & $103(52.82 \%)$ & $48(40.68 \%)$ & $26(45.61 \%)$ & \\
\hline Hemofiltration (HF) & $0(0 \%)$ & $14(7.18 \%)$ & $12(10.17 \%)$ & $6(10.53 \%)$ & \\
\hline Hemodlafiltration (HDF) & $4(23.53 \%)$ & $47(24.10 \%)$ & $36(30.51 \%)$ & $15(26.32 \%)$ & \\
\hline Acetate free blofiltration (AFB) & $1(5.88 \%)$ & $25(12.82 \%)$ & $19(16.10 \%)$ & $9(15.79 \%)$ & \\
\hline Other types of dialysls & $0(0 \%)$ & $6(3.08 \%)$ & $3(2.54 \%)$ & $1(1.75 \%)$ & \\
\hline Prevlous kldney transplant, n (\%) & $2(11.76 \%)$ & $30(15.38 \%)$ & $19(16.10 \%)$ & $3(5.26 \%)$ & 0.218 \\
\hline Hypertension, n (\%) IPA & $9(52.94 \%)$ & $158(81.03 \%)$ & $92(77.97 \%)$ & $45(78.95 \%)$ & 0.061 \\
\hline Angina, $n(\%)$ & $1(5.88 \%)$ & $30(15.38 \%)$ & $22(18.64 \%)$ & $11(19.30 \%)$ & 0.102 \\
\hline Myocardial Infarction, n (\%) & $2(11.76 \%)$ & 31 (15.90\%) & $28(23.73 \%)$ & $12(21.05 \%)$ & 0.298 \\
\hline Atrial fibrillation, $\mathrm{n}\left(\%_{0}\right)$ & $2(11.76 \%)$ & $23(11.79 \%)$ & $19(16.10 \%)$ & $7(12.28 \%)$ & 0.735 \\
\hline Heart fallure, $\mathrm{n}(\%)$ & $1(5.88 \%)$ & $18(9.23 \%)$ & $13(11.02 \%)$ & $7(12.28 \%)$ & 0.824 \\
\hline Dlabetes mellitus, n (\%) & $1(5.88 \%)$ & $27(13.85 \%)$ & $31(26.27 \%)$ & $26(45.61 \%)$ & $<0.001$ \\
\hline Perlpheral vascular disease, n (\%) & & & & & 0.166 \\
\hline No & $14(82.35 \%)$ & $129(66.15 \%)$ & $77(65.25 \%)$ & $33(57.89 \%)$ & \\
\hline Asymptomatic & $2(11.76 \%)$ & $50(25.64 \%)$ & $29(24.58 \%)$ & $17(29.82 \%)$ & \\
\hline Intermittent claudication & $1(5.88 \%)$ & $15(7.69 \%)$ & 9 (7.63\%) & $3(5.26 \%)$ & \\
\hline Amputation & $0(0 \%)$ & $1(0.51 \%)$ & $3(2.54 \%)$ & $4(7.02 \%)$ & \\
\hline Cerebrovascular accident, $\mathrm{n}$ (\%) & & & & & 0.829 \\
\hline No & $16(94.12 \%)$ & $177(90.76 \%)$ & $104(88.14 \%)$ & $49(85.96 \%)$ & \\
\hline Stroke & $1(5.88 \%)$ & $9(4.62 \%)$ & $7(5.93 \%)$ & $3(5.26 \%)$ & \\
\hline Other type & $0(0 \%)$ & $9(4.62 \%)$ & $7(5.93 \%)$ & $5(8.78 \%)$ & \\
\hline
\end{tabular}

\begin{tabular}{|c|c|c|c|c|c|}
\hline Variable & $\begin{array}{r}\text { Patients underweight } \\
\text { BMI }<18.5 \\
(\mathrm{n}=17,4.39 \%)\end{array}$ & $\begin{array}{r}\text { Patients normal } \\
\text { weight } 18.5 \leq B M I<25 \\
(n=195,50.39 \%)\end{array}$ & $\begin{array}{r}\text { Patients overweight } \\
25 \leq \mathrm{BMI}<30 \\
(\mathrm{n}=118,30.49 \%)\end{array}$ & $\begin{array}{r}\text { Patients obese } \\
\text { BMI } \geq 30 \\
(\mathrm{n}=57,14.73 \%)\end{array}$ & p-Value \\
\hline \multicolumn{6}{|l|}{ Routine blochemical profile } \\
\hline Ca, mg/dL (medlan) & $8.8(8.6,9.1)$ & $9.2(8.8,9.6)$ & $9.15(8.8,9.6)$ & $9(8.5,9.4)$ & 0.118 \\
\hline $\mathrm{Ca}, \mathrm{mg} / \mathrm{dL}$, mean $\pm \mathrm{SD}$ (not normal dlstributed) & $8.90 \pm 0.73$ & $9.18 \pm 0.71$ & $9.21 \pm 0.63$ & $9.04 \pm 0.66$ & 0.183 \\
\hline $\mathrm{P}, \mathrm{mg} / \mathrm{dL}$, mean $\pm \mathrm{SD}$ (not normal dlstributed) & $4.58 \pm 1.38$ & $4.80 \pm 1.24$ & $4.79 \pm 1.30$ & $4.80 \pm 1.28$ & 0.928 \\
\hline $\mathrm{P}, \mathrm{mg} / \mathrm{dL}$ (medlan) & $4.2(3.9,5.4)$ & $4.6(3.72,5.6)$ & $4.65(4,5.4)$ & $4.7(4,5.5)$ & 0.822 \\
\hline Alkaline phosphatase, $\mathrm{U} / \mathrm{L}$ (medlan) & $90(72,202)$ & $83(69,114)$ & $83.5(60,110)$ & $80(61,104)$ & 0.089 \\
\hline PTH, pg/mL (medlan) & $289(130,446)$ & $244(150,384)$ & $239.5(132,384)$ & $217(126,355)$ & 0.782 \\
\hline Albumln, g/dL (medlan) & $3.5(3.2,3.8)$ & $3.8(3.5,4.1)$ & $3.9(3.5,4.1)$ & $3.9(3.5,4.1)$ & 0.114 \\
\hline CRP, mg/L (medlan) & $2.25(1.34,14.2)$ & $1(0.39,5)$ & $2.9(0.5,6.7)$ & $1.5(0.68,4.1)$ & 0.043 \\
\hline $\mathrm{KT} / \mathrm{V}$, mean $\pm \mathrm{SD}$ & $1.34 \pm 0.34$ & $1.25 \pm 0.28$ & $1.26 \pm 0.24$ & $1.20 \pm 0.24$ & 0.279 \\
\hline Aluminlum, mcg/L (medlan) & $10(7,13)$ & $12(9,22)$ & $12(8,17)$ & $12(6.9,25)$ & 0.630 \\
\hline Total cholesterol, mg/dL (medlan) & $172(156,185)$ & $164(134,191)$ & $170(146,197)$ & $171(146,193)$ & 0.191 \\
\hline Triglycerldes, mg/dL (medlan) & $141(117,158)$ & $128(97,179)$ & $162.5(121,221)$ & $200(147,265)$ & 0.001 \\
\hline HDL cholesterol, mg/dL (medlan) & $45(33,53)$ & $42(34,54)$ & $39(31,47)$ & $35(30,44)$ & 0.001 \\
\hline LDL cholesterol, mg/dL (median) & $97(68,120)$ & $84.75(68,111.5)$ & $96(74,120)$ & $91(65,113)$ & 0.223 \\
\hline 25(OH)D, ng/mL (medlan) & $22.2(17.1,36.8)$ & $31(20.4,48.5)$ & $28.75(18,38.9)$ & $25.1(19.1,40.8)$ & 0.098 \\
\hline BGP total, mcg/L (medlan) & $204(135,437.8)$ & $217(119,373)$ & $152(83.2,251)$ & $104(62.7,230)$ & $<0.001$ \\
\hline BGP undecarboxylated, ng/mL (medlan) & $12.4(4.6,29.15)$ & $11.96(6.38,18)$ & $11.03(4.04,17.2)$ & $8.1(2.82,12.84)$ & 0.009 \\
\hline MGP total, nmol/L (medlan) & $19.84(11.15,38.05)$ & $18.9(12.71,29.24)$ & $17.67(12.7,28.89)$ & $20.01(13.21,34.71)$ & 0.836 \\
\hline MGP decarboxylated, nmol/L (medlan) & $683(535,1104)$ & $533(268,908)$ & $560.19(309,942)$ & $683(259,1062)$ & 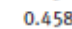 \\
\hline Magnesemla, mg/dL (medlan) & $2.45(2.05,2.85)$ & $2.3(2,2.6)$ & $2.3(2.1,2.8)$ & $2.1(2,2.6)$ & 0.488 \\
\hline$(n=139)$ & $(n=4)$ & $(n=67)$ & $(n=43)$ & $(n=25)$ & \\
\hline 'Magnesemla, mg/dL (medlan)' (not normal dlstributed by all group) & $2.45 \pm 0.54$ & $2.44 \pm 0.65$ & $2.47 \pm 0.50$ & $2.25 \pm 0.47$ & 0.468 \\
\hline$(n=139)$ & $(n=4)$ & $(n=67)$ & $(n=43)$ & $(n=25)$ & \\
\hline
\end{tabular}

Significant differences ( $p \leq 0.05)$ are shown In bold. 
Table 2. Therapy by BMI.

\begin{tabular}{|c|c|c|c|c|c|}
\hline $\begin{array}{l}\text { Drugs prescribed to } \\
\text { patients }\end{array}$ & $\begin{array}{r}\text { Patients underweight } \\
\text { BMI }<18.5 \\
(\mathrm{n}=17,4.39 \%)\end{array}$ & $\begin{array}{r}\text { Patients normal } \\
\text { weight } 18.5 \leq \text { BMI }<25 \\
(n=195,50.39 \%)\end{array}$ & $\begin{array}{r}\text { Patients overweight } \\
25 \leq B M I<30 \\
(n=118,30.49 \%)\end{array}$ & $\begin{array}{r}\text { Patients obese } \\
\text { BMI } \geq 30 \\
(n=57,14.73 \%)\end{array}$ & p-Value \\
\hline Warfarin, n (\%) & $1(5.88 \%)$ & $22(11.28 \%)$ & $16(13.56 \%)$ & $7(12.28 \%)$ & 0.807 \\
\hline Steroid, $\mathbf{n}(\%)$ & $1(5.88 \%)$ & $10(5.13 \%)$ & $7(5.93 \%)$ & $3(5.26 \%)$ & 0.922 \\
\hline Thyroid hormones, n (\%) & $1(5.88 \%)$ & $19(9.74 \%)$ & $10(8.47 \%)$ & $10(17.54 \%)$ & 0.254 \\
\hline Antibiotics, $\mathrm{n}(\%)$ & $1(5.88 \%)$ & $6(3.08 \%)$ & $6(5.08 \%)$ & $3(5.26 \%)$ & 0.769 \\
\hline Antiepileptic, n (\%) & $0(0.00 \%)$ & $8(4.10 \%)$ & $4(3.39 \%)$ & $2(3.51 \%)$ & 0.852 \\
\hline Statin therapy, n (\%) & $2(11.76 \%)$ & $51(26.15 \%)$ & $45(38.14 \%)$ & $28(49.12 \%)$ & 0.001 \\
\hline Beta-blockers, n (\%) & $6(35.29 \%)$ & $71(36.41 \%)$ & $44(37.29 \%)$ & $23(40.35 \%)$ & 0.956 \\
\hline Antidiabetics, n (\%) & $0(0 \%)$ & $0(0 \%)$ & $1(0.85 \%)$ & $6(10.53 \%)$ & $<0.001$ \\
\hline Insulin, $\mathrm{n}(\%)$ & $0(0 \%)$ & $20(10.26 \%)$ & $21(17.80 \%)$ & $17(29.82 \%)$ & 0.001 \\
\hline Anti-gastric, n (\%) & $14(82.35 \%)$ & $148(75.90 \%)$ & $88(74.58 \%)$ & $47(82.46 \%)$ & 0.630 \\
\hline Aluminium, $\mathrm{n}(\%)$ & $4(23.53 \%)$ & $49(25.13 \%)$ & $26(22.03 \%)$ & $17(29.82 \%)$ & 0.734 \\
\hline Calcium carbonate, $\mathrm{n}(\%)$ & $3(17.65 \%)$ & $62(31.79 \%)$ & $46(38.98 \%)$ & $21(36.84 \%)$ & 0.267 \\
\hline Calcium acetate, $\mathrm{n}(\%)$ & $0(0 \%)$ & $10(5.13 \%)$ & $3(2.54 \%)$ & $8(14.04 \%)$ & 0.011 \\
\hline Sevelamer, n (\%) & $6(35.29 \%)$ & $90(46.15 \%)$ & $47(39.83 \%)$ & $20(35.09 \%)$ & 0.386 \\
\hline Lanthanum, n (\%) & $3(17.65 \%)$ & $24(12.31 \%)$ & $19(16.10 \%)$ & $10(17.54 \%)$ & 0.668 \\
\hline Oral calcitriol, n (\%) & $7(41.18 \%)$ & $90(46.15 \%)$ & $55(46.61 \%)$ & $25(43.86 \%)$ & 0.965 \\
\hline Intravenous calcitriol, n (\%) & $0(0 \%)$ & $4(2.05 \%)$ & $5(4.24 \%)$ & $3(5.26 \%)$ & 0.448 \\
\hline Vitamin D analogues, $\mathbf{n}(\%)$ & $4(23.53 \%)$ & $43(22.05 \%)$ & $18(15.25 \%)$ & $12(21.05 \%)$ & 0.503 \\
\hline Calcimimetics, n (\%) & $3(17.65 \%)$ & $36(18.46 \%)$ & $21(17.80 \%)$ & $15(26.32 \%)$ & 0.556 \\
\hline
\end{tabular}

Significant differences $(p \leq 0.05)$ are shown in bold.

Table 3: Vitamin K status in patients

\begin{tabular}{|c|c|c|c|c|c|}
\hline Vitamers & $\begin{array}{r}\text { Patients underweight } \\
\text { BMI }<18.5 \\
(n=17,4.39 \%)\end{array}$ & $\begin{array}{r}\text { Patients normal weight } \\
18.5 \leq \text { BMI }<25 \\
(n=195,50.39 \%)\end{array}$ & $\begin{array}{r}\text { Patients overweight } \\
25 \leq \text { BMI<30 } \\
(n=118,30.49 \%)\end{array}$ & $\begin{array}{r}\text { Patients obese } \\
\text { BMI } \geq 30 \\
(\mathrm{n}=57,14.73 \%)\end{array}$ & p-Value \\
\hline $\mathrm{K} 1, \mathrm{ng} / \mathrm{mL}$ (median) & $0.40(0.31,0.53)$ & $0.63(0.36,1.12)$ & $0.63(0.29,0.98)$ & $0.96(0.51,1.32)$ & 0.012 \\
\hline K1/triglycerides, ng/mL (median) & $0.24(0.14,0.40)$ & $0.50(0.25,0.83)$ & $0.40(0.20,0.70)$ & $0.44(0.20,1.00)$ & 0.022 \\
\hline MK4 ng/mL (median) & $0.50(0.07,0.67)$ & $0.56(0.21,0.67)$ & $0.50(0.23,0.67)$ & $0.48(0.22,0.67)$ & 0.976 \\
\hline MK4/triglycerides ng/mL (median) & $0.32(0.05,0.51)$ & $0.43(0.16,0.51)$ & $0.35(0.13,0.51)$ & $0.31(0.12,0.51)$ & 0.390 \\
\hline MK5 $\mathrm{ng} / \mathrm{mL}$ (median) & $1.00(0.38,1.18)$ & $1.00(0.54,1.02)$ & $1.00(0.43,1.01)$ & $1.00(0.40,1.00)$ & 0.581 \\
\hline MK5/triglycerides, ng/mL (median) & $0.75(0.36,0.97)$ & $0.75(0.40,0.75)$ & $0.75(0.27,0.76)$ & $0.51(0.23,0.75)$ & 0.090 \\
\hline MK6 ng/mL (median) & $0.44(0.37,0.63)$ & $0.55(0.24,0.76)$ & $0.46(0.19,0.63)$ & $0.47(0.13,0.63)$ & 0.514 \\
\hline MK6/triglycerides, ng/mL (median) & $0.35(0.26,0.47)$ & $0.44(0.15,0.61)$ & $0.28(0.11,0.47)$ & $0.24(0.08,0.47)$ & 0.017 \\
\hline MK7 ng/mL (median) & $0.98(0.58,1.57)$ & $1.15(0.47,1.19)$ & $1.06(0.52,1.20)$ & $0.81(0.32,1.15)$ & 0.431 \\
\hline MK7/triglycerides, $\mathrm{ng} / \mathrm{mL}$ (median) & $0.67(0.39,1.43)$ & $0.87(0.36,0.96)$ & $0.70(0.31,0.87)$ & $0.42(0.19,0.87)$ & 0.005 \\
\hline
\end{tabular}

Significant differences $(\mathrm{p} \leq 0.05)$ are shown in bold. 
Table 4: Linear regression model with outcome MK7/triglycerides (log-transformed) adjusted for BMI (log-transformed), HDL cholesterol (log-transformed), dialysis vintage (log-transformed), age, gender, MK4 (log-transformed) and decarboxylated MGP (log-transformed).

\begin{tabular}{lrr}
\hline Variable & $\boldsymbol{\beta}$ & p-Value \\
\hline Log BMI & -0.159 & 0.003 \\
Log HDL cholesterol, mg/dL & 0.123 & 0.026 \\
Log dialysis vintage & -0.046 & 0.382 \\
Age & -0.030 & 0.570 \\
Gender & -0.064 & 0.232 \\
Log MK4, ng/mg & 0.235 & $<0.001$ \\
Log decarboxylated MGP, nmol/L & -0.083 & 0.106 \\
\hline
\end{tabular}

Significant differences $(\mathrm{p} \leq 0.05)$ are shown in bold.

Table 5: Linear regression model with outcome total BGP (log-transformed) adjusted for BMI (logtransformed), age, gender, dialysis vintage (log-transformed), alkaline phosphatase (logtransformed), peripheral vascular disease and DM.

\begin{tabular}{lrr}
\hline Variable & $\boldsymbol{\beta}$ & p-Value \\
\hline Log BMI & -0.119 & 0.012 \\
Age & -0.255 & $<0.001$ \\
Gender & 0.077 & 0.086 \\
Log dialysis vintage & 0.103 & 0.025 \\
Log alkaline phosphatase, U/L & 0.277 & $<0.001$ \\
Peripheral vascular disease & -0.116 & 0.016 \\
DM & -0.119 & $\mathbf{0 . 0 1 6}$ \\
\hline
\end{tabular}

Significant differences $(\mathrm{p} \leq 0.05)$ are shown in bold. 
Figure 1

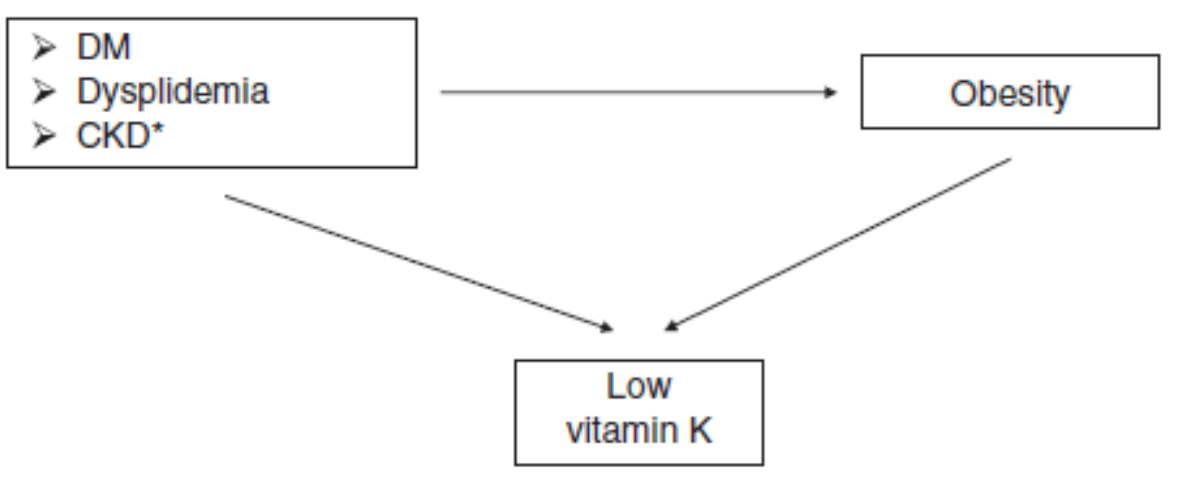


Figure 2

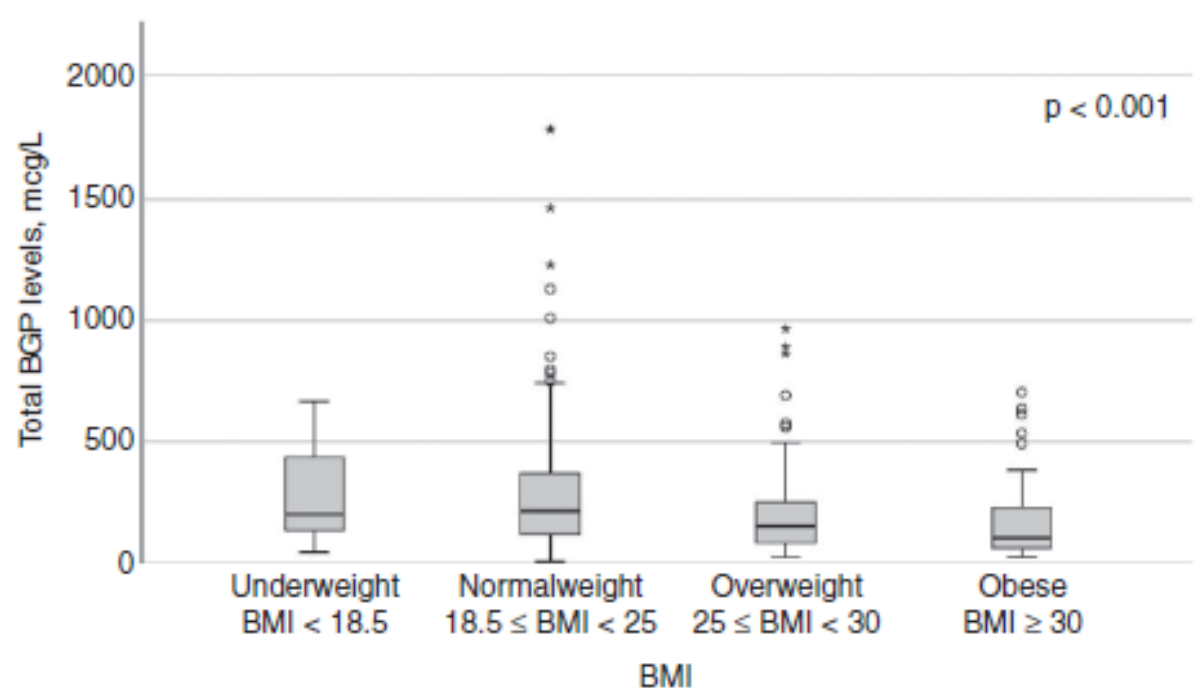


Figure 3

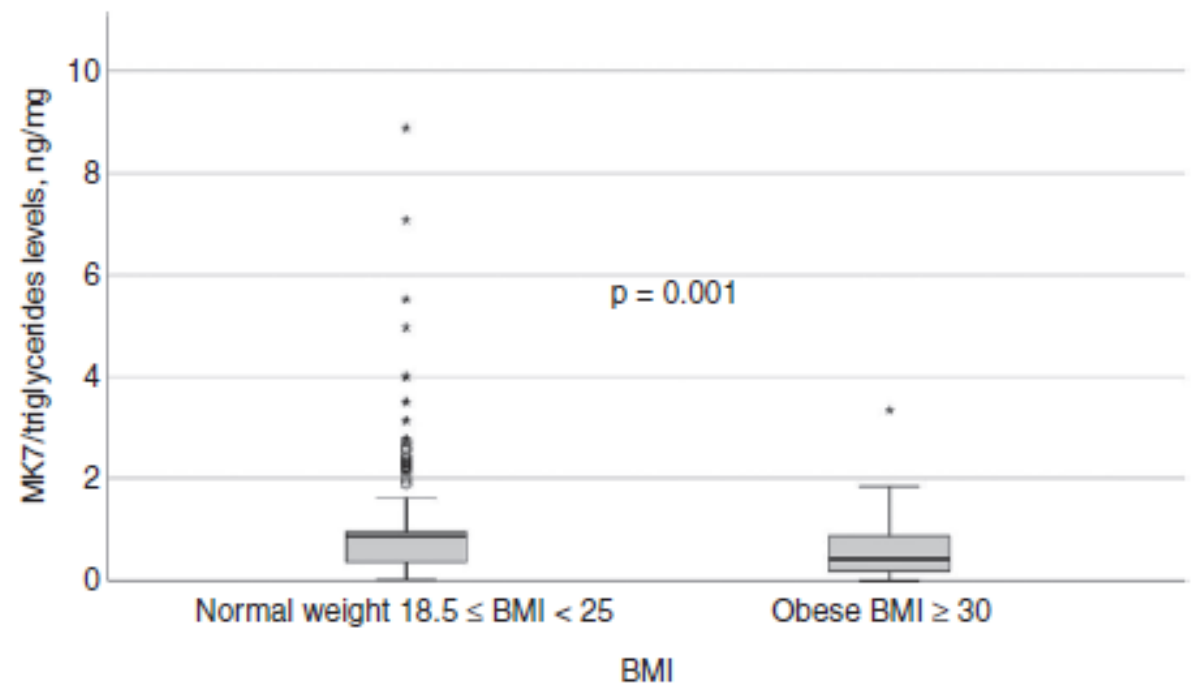

